\title{
DÜBLIN
}

Technological University Dublin

ARROW@TU Dublin

\section{Impact of plasma treatment on acoustic properties of natural cellulose materials}

\author{
Sanja S. Pavlović \\ Belgrade Polytechnics \\ Snežana B. Stanković \\ University of Belgrade \\ Andrijana Žekić \\ University of Belgrade
}

See next page for additional authors

Follow this and additional works at: https://arrow.tudublin.ie/scschphyart

Part of the Plasma and Beam Physics Commons

\section{Recommended Citation}

Pavlović, S.S., Stanković, S.B., Žekić, A. et al. Impact of plasma treatment on acoustic properties of natural cellulose materials. Cellulose 26, 6543-6554 (2019). DOI: 10.1007/s10570-019-02547-1

This Article is brought to you for free and open access by the School of Physics \& Clinical \& Optometric Science at ARROW@TU Dublin. It has been accepted for inclusion in Articles by an authorized administrator of ARROW@TU Dublin. For more information, please contact arrow.admin@tudublin.ie, aisling.coyne@tudublin.ie, gerard.connolly@tudublin.ie.

Funder: Ministry of Education and Science, Republic of Serbia 


\section{Authors}

Sanja S. Pavlović, Snežana B. Stanković, Andrijana Žekić, Miloš Nenadović, Dušan M. Popović, Vladimir Milosavljevic, and Goran B. Poparić 


\title{
Impact of plasma treatment on acoustic properties of natural cellulose materials
}

\author{
Sanja S. Pavlović • Snežana B. Stanković • Andrijana Žekić • Miloš Nenadović • \\ Dušan M. Popović • Vladimir Milosavljević • Goran B. Poparić
}

Received: 17 January 2019/Accepted: 30 May 2019/Published online: 4 June 2019

(C) Springer Nature B.V. 2019

\begin{abstract}
Low-temperature plasma is widely used in many surface treatment technologies for modifications of the physical properties of different polymeric materials. In the present work, we have examined the modification of acoustical properties of natural cellulose materials (cotton, hemp) by the radiofrequency argon plasma. We have observed an increase of the sound absorption coefficient due to the plasma treatment for certain range of applied powers. An analysis of elementary processes which
\end{abstract}

happened during plasma-material interaction was conducted. Additional analyses related to material characterizations were performed in order to resolve structural and chemical changes of plasma treated materials. The micro-mechanical modification of treated materials, which happened upon the retrieved structural and chemical changes, was related to the modification of its acoustical properties in order to explain the observed effect.
S. S. Pavlović

Belgrade Polytechnics, Brankova 17, 11000 Belgrade, Serbia

\section{S. B. Stanković $(\bowtie)$}

Textile Engineering Department, Faculty of Technology and Metallurgy, University of Belgrade, Karnegijeva 4, 11120 Belgrade, Serbia

e-mail: stankovic@tmf.bg.ac.rs

A. Žekić · D. M. Popović · V. Milosavljević ·

G. B. Poparić

Faculty of Physics, University of Belgrade, Studentski Trg

12, P.O. Box 44, 11000 Belgrade, Serbia

\author{
M. Nenadović \\ Vinča Institute of Nuclear Sciences, University of \\ Belgrade, P.O. Box 522, Mike Petrovića Alasa 12-14, \\ 11001 Belgrade, Serbia \\ V. Milosavljević \\ School of Physics and Clinical and Optometric Sciences, \\ Technological University Dublin, Dublin, Ireland
}




\section{Graphic abstract}
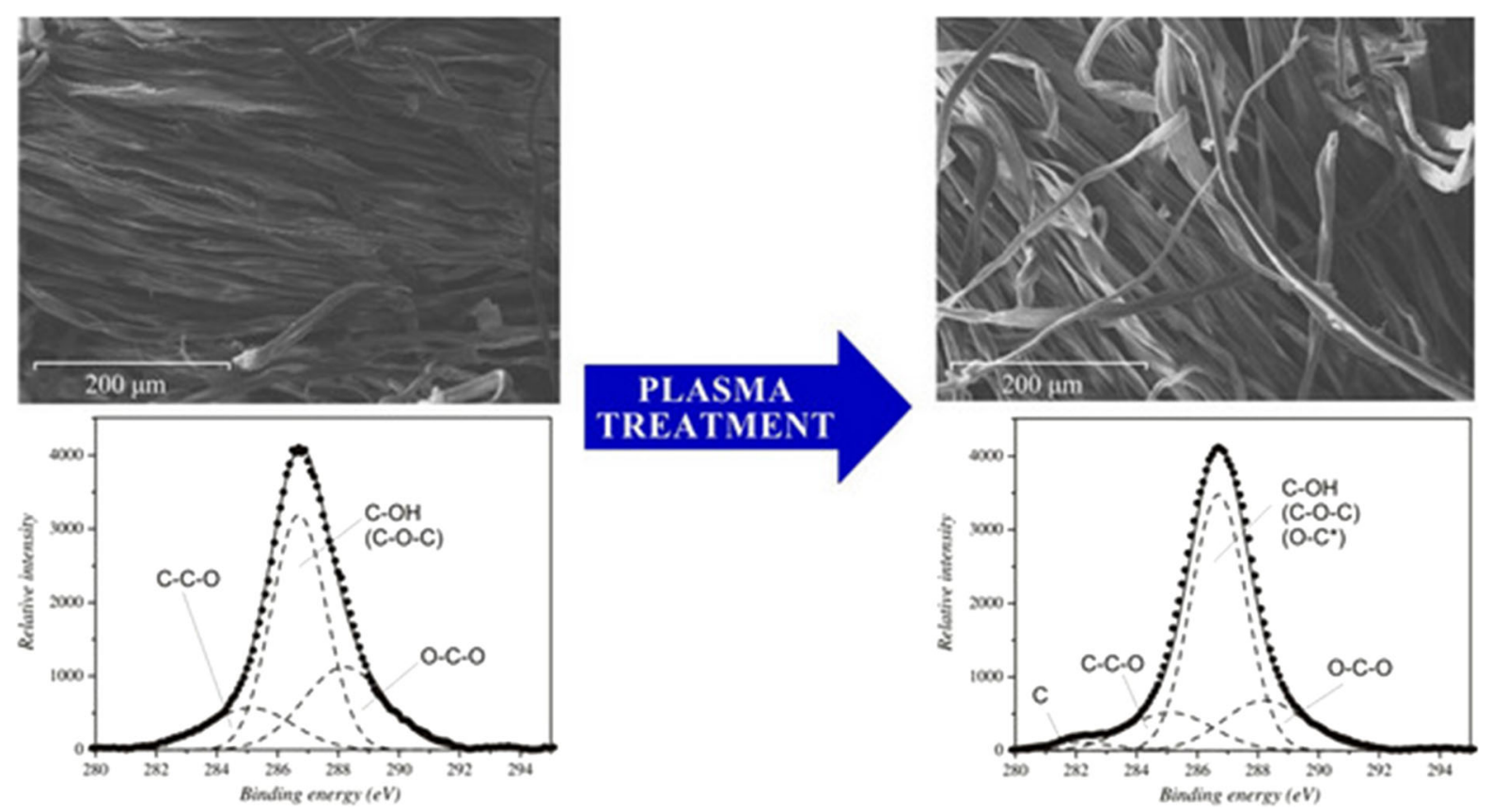

Keywords Cotton - Hemp - Radio-frequency argon plasma $\cdot$ Plasma treatment $\cdot$ Acoustic properties

\section{Introduction}

Various plasma polymeric material modification technologies are based on plasma discharges in different gases. Due to plasma treatment, numerous chemical and physical changes occur in the exposed materials, whereby the treated materials change their physical and chemical properties. Frequently used gas in plasma discharges is argon, which plays a very important role in a large number of plasma-material modifications (Vidaurre et al. 2002; Slepička et al. 2013). The pure argon plasma is suitable in the cases when the prevention of oxidation processes during plasma treatments is needed (Grace and Gerenser 2003). For the plasma treatments, beside commonly used direct current (DC) plasma discharges, the plasma induced by radio-frequent (RF) electric field is used, as well. It has been shown that the processing of plasma-surface modifications in RF plasmas can be effectively performed at much lower pressures compared to DC plasmas, resulting in lowering the gas and energy consumptions (Baldwin et al. 1998).

Cellulose is known as the most frequently used natural polymeric material. The natural cellulose fibers usually obtained from both cotton flowers and bast fiber stalks (flax, hemp, jute), are used as the basic commodity for the production of textile products. The fabrics produced from natural cellulose fibers are primarily used in the clothing industry, but there are many other applications, especially in the automotive industry and in the construction and building industry. Natural cellulose fibers and their products, either in the form of conventional or industrial textiles can be very effective in sound absorption thanks to their intrinsic porosity. Nowadays they play an important role in creating an acoustically pleasant environment (room acoustics, automotive acoustics, industrial noise control) (Beradi and Iannace 2015). Natural fibers have received much attention for acoustical uses due to their renewable sourcing, biodegradability, recyclability and very low toxicity (Asdrubali et al. 2012). Their competitiveness has also come from their good mechanical properties and low density, as well as from their environmentally-friendly and cost-effective production (Arenas and Crocker 2010). As a consequence, a number of investigations dealt with the 
sound absorption properties of natural fiber assemblies and fabrics. One of the most widespread ways of using natural fibers is for thermo-acoustic function in the form of fiber wool or web in building and automotive sectors, and therefore, quite a lot of studies were devoted to the acoustic absorption properties of raw natural fibers assemblies (Nick et al. 2002; Yang et al. 2010; Arenas and Crocker 2010; Oldham et al. 2011; Fouladi et al. 2011; Xiang et al. 2013; Beradi and Iannace 2015, 2017; Beradi et al. 2017). New composites in which glass fibers were replaced by natural fibers (biocomposites) appeared in the last decade of the twentieth century to be used as building materials, automotive parts, in special sporting equipment and aerospace industry (Marsh 2003). Since the satisfactory acoustic behavior is one of their essential performances, a range of investigations of sound absorption properties of various fiber-reinforced composites have been conducted over the years (Zulkifh et al. 2008; Buksnowitz et al. 2010; Fatima and Mohanty 2011; Krucinska et al. 2015; Echeverria et al. 2019). In addition to composite materials in which fibers are mixed with other fibrous or non-fibrous components, common textile materials are in use for a variety of purposes in residential and occupational environments such as upholstery materials, wall coverings, window coverings etc. Natural fiber based nonwovens are widely used thanks to their lightweight, formability (easily conforms to various shapes) and flexibility (Vasile and Van Langenhove 2004). Extensive research have been done on sound absorption properties of such nonowovens, some of which are referred in the manuscript (Parikh et al. 2006: Thilagavathi et al. 2010; Kucuk and Korkmaz 2012; Rwawiire et al. 2017; Islam and Alam 2018). Limited research has been conducted in the case of woven (Shoshani and Rosenhouse 1990, 2012, 2013; Tang et al. 2018) and knitted fabrics (Dias and Monaragala 2006; Dias et al. 2007: Honarvar et al. 2010; Stankovic et al. 2016), although they can have an important role in the design of sound absorptive materials when aesthetically pleasing appearance is needed (interior decorations).

In addition to experimental investigations, a number of research works have addressed the sound absorption modeling, both theoretical and empirical, of fiber assemblies or products. Although full theoretical sound absorption modeling is out of scope of this study, we refer to several works (Zwikker and
Kosten 1949; Biot 1962; Attenborough 1982; Dahl et al. 1990; Shoshani and Yakubov 1999; Yang et al. 2010; Honarvar et al. 2010). In 1970, Delany and Bazley (1970) introduced the first empirical model for fibrous absorbent material with a fiber diameter between 1 and $10 \mu \mathrm{m}$. They proposed simple powerlaw relations obtained by best-fitting a large amount of experimental data. Garai and Pompoli (2005) revised the Delany-Bazley model by best fitting the measured values of the relevant physical parameters for a set of polymer fibers with diameter ranging from 18 to $48 \mu \mathrm{m}$. Oldham et al. (2011) found in their investigation that these two models predicted quite well the acoustical properties of fibrous absorbers with fiber diameter up to approximately $60 \mu \mathrm{m}$. As reported elsewhere (Wang and Torng 2001; Rwawiire et al. 2017), the Delany-Bazley model is inadequate for very low and very high frequencies. However, in Fouladi's investigation (2011) the model was a good approximation for overall broadband trend of acoustical behavior. Besides Garai and Pompeli, other authors revised the Delany-Bazley model by providing the coefficients other than those originally proposed by Delany and Bazley (Miki 1990; Arenas et al. 2014; Beradi and Iannace 2017), but their model has been still widely used to describe acoustical characteristics of fibrous materials.

The aim of this work was to investigate the possible changes of the acoustical properties of natural cellulose materials caused by the plasma treatment. Surprisingly little research dealt with the effect of environmentally benign plasma treatment on acoustical properties of natural cellulose materials. In fact, to the best of authors' knowledge, the only published paper dealing with the influence of plasma treatment on sound absorption properties of textile materials proved the positive effect of plasma treatment on jute and kenaf (and polyester) nonwovens (Youngjoo and Gilsoo 2010). To achieve the modification of the materials, we used the RF plasma reactor with the argon as the working gas. The pre and post plasma treatment analyses of acoustical properties were done and confirmed the expected changes. Additional analyses related to the structural and chemical characterization of the materials were conducted in order to understand better the obtained effect. An adequate analysis of elementary processes during the plasma treatment which could lead to observed structural and chemical changes was performed. We also discussed 
the potential micro-mechanical changes of cellulose materials which could happen during the plasma treatment and which could consequently lead to the observed changes of their acoustical properties. These changes were confirmed by the Delany-Bazley model used for predicting the sound absorption coefficient for the untreated and plasma treated fabrics.

\section{Experimental}

\section{Materials}

Textile fabrics can have various forms depending on the fiber packing formats. In nonwoven fabrics, fibers are randomly oriented in the layers which are bonded together by mechanical, chemical or thermal treatments. In woven or knitted fabrics, fibers have the configuration of parallel fiber bundle which are directionally oriented with an angle relative to yarn axis coming from the twist (which give cohesion to the yarn). To include both kinds of fiber packing format, the natural cellulose materials used in our investigations were a mixture of cotton and hemp 50\%/50\% in a form of knitted fabrics or cotton fiber assemblies. The basic characteristics of the material used in the form of rib (1:1) knitted fabrics are: stitch density: 64-72 $\mathrm{cm}^{-2}$; thickness: $2.36-2.50 \mathrm{~mm}$; surface density (areal density): $950-1000 \mathrm{~g} / \mathrm{m}^{2}$ and bulk density: $0.38-0.42 \mathrm{~g} / \mathrm{cm}^{3}$. The basic characteristics of the fiber assemblies are: thickness: $2.45-2.55 \mathrm{~mm}$ and bulk density: $0.095-0.15 \mathrm{~g} / \mathrm{cm}^{3}$. These fiber assemblies consisted of the fiber layers compressed to have a thickness similar to that of the knitted fabrics and to form the nonwoven-like structure but without bonding treatment. In such a way, cohesion in the fiber assemblies was arisen from the friction between the fibers such as in insulation fiber wool.

\section{Plasma processing}

The method used for the modification of the natural cellulose materials was the plasma treatment in the RF capacitively coupled plasma (CCP) reactor filled by the argon gas. The plasma reactor was placed in the cylindrical stainless steel chamber. In order to control gas or gas mixture purity, a vacuum system equipped with gas mass flow controllers was used. The Ar gas was introduced in the previously evacuated plasmas chamber by a vacuum pump, with controlled mass flow of the gas. The high voltage RF generator was connected to the central electrode of the chamber, while the ground was connected to the outer body of the chamber. The standard $13.56 \mathrm{MHz}$ frequency was applied for RF discharges. The argon gas was fed through mass flow controller at gas flow of $2 \mathrm{sccm}$. The pressure of the argon gas during our plasma treatments was about 1 Torr, which is within the approximately evaluated range of 1-100 mbar estimated as an optimum for achieving maximal plasma penetration effects (Poll et al. 2001). The applied powers used during plasma discharges were in the range from 40 to $100 \mathrm{~W}$. The treated samples of materials were set in plasma reactor by using specially designed feedthrough connector and the treatments lasted for $20 \mathrm{~min}$ (this was an estimated optimum). In order to measure and control plasma conditions, the optical emission spectroscopy (OES) was employed.

\section{Characterizations}

\section{Sound absorption measurement}

The measurements of the sound absorption coefficient (SAC) of the examined materials were performed before and after the plasma treatments. We used a standard two-microphone impedance tube which has been designed as per the ISO 10534-2:1998 standard (Acoustics-Determination of sound absorption coefficient and impedance in impedance tubes-Part 2 : Transfer-function method). The diameter of the tube $(29 \mathrm{~mm})$ was set up for measuring SAC in the high frequency range (up to $5000 \mathrm{~Hz}$ ). According to ISO 10534 standard, for each examined material the SAC measurements were performed for three samples with repetition of at least three times for each of them, and their average was calculated. In consideration of the fact that the structure of the fiber assemblies or the knitted fabrics, and constituent yarns, would be changed by any finishing treatment (physico-mechanical or chemical), the investigation of their sound absorption ability before plasma treatment was conducted in the grey state.

\section{SEM/EDAX analysis}

The examined materials were inspected using a JEOL JSM 840-A Scanning Electron Microscope (SEM) 
equipped with an Oxford Instruments INCA Penta FET $\times 3$ Energy-Dispersive $\mathrm{X}$-ray spectroscopy (EDX) micro analyzer. The SEM/EDX analyses were performed before the plasma treatment (pristine samples), a few hours and 7 days upon the plasma treatment.

\section{XPS analysis}

XPS analysis was performed using a SPECS instrument for surface characterization is described in detail elsewhere (Kljajević et al. 2017). Shortly, photoelectron emission was excited by monochromatic $\mathrm{Al} \mathrm{K \alpha}$ line with photon energy of $1486.67 \mathrm{eV}$. Detailed spectra of the main photoelectron lines were taken in the fixed analyzer transmission mode with a pass energy of $20 \mathrm{eV}$ (FAT 20), an energy step of $0.1 \mathrm{eV}$ and a dwell time of $2 \mathrm{~s}$. Charging compensation was performed using an electron flood gun and the binding energy axis was adjusted according to the position of the nitrogen $\mathrm{N}$ 1s line. The composition analysis was performed according to the characteristic photoelectron line intensities after background removal, using the atomic sensitivity factors provided by the manufacturer. The photoelectron lines were fitted to peaks with accompanying software package.

\section{Experimental results}

Changes in the SAC upon plasma modification

The SAC spectra, in the frequency range $0-4800 \mathrm{~Hz}$, for both types of samples (knitted fabrics and fiber assemblies) are shown in Fig. 1a, b, respectively. In both figures it can be seen SAC spectra for both untreated and the plasma treated samples. As can be seen from the figures, the knitted fabrics are characterized by higher SAC in the whole frequency range. This can be explained by higher bulk density range of the knitted samples than that of the fiber assemblies. With an increase in the number of fibers per unit volume the energy loss increases due to an increase in surface friction (Seddeq 2009). Plasma treatment results in an increase in SAC for almost the whole frequency range. In other words, the plasma treatment of the natural cellulose fibrous materials increases their ability to absorb mechanical sound energy. In Fig. 1a the SAC coefficient for the knitted samples treated under different applied power is shown. It can be seen that an increase in the SAC is especially pronounced for the medium values of the applied power of RF plasma. In Fig. $1 b$ beside the measured SAC spectra, the theoretically proposed spectra are also shown in order to compare them, which would be discussed in the next section.

It is well known that the plasma treatment of the materials is usually followed by the relaxation processes, i.e. the effect of the treatment may be significantly impacted by the aging. For example, the plasma treatment often results in hydrophilization of the surfaces, and the hydrophilicity of the surface may be stable for at least $24 \mathrm{~h}$ (Zemljič et al. 2009). In order to check out if there are any changes in the acoustical properties of the plasma treated materials upon the time, we repeated the SAC measurements 7 days, 3 and 9 months upon the plasma treatment, respectively. We did not detect any changes in SAC spectra, which is the solid evidence that the plasma treatment permanently changed the acoustical properties of the materials.

In order to explain the causes of the material modification, we firstly excluded the thermal effects as a reason of the modification, because the increase in the temperature of the samples during plasma exposition was less than $25^{\circ} \mathrm{C}$. In an attempt to explain the elementary processes, which happened during plasma-material interaction, and which are pivotal to modification of the treated material, we conducted the additional analyses. Further, we assumed that the pivotal role in the modification of polymeric materials by the inert gases plasma plays the interactions of free electrons and active species (ions, excited and metastable atoms) with polymeric molecules (ArefiKhonsari and Tatoulian 2008). Such interactions cause the bond-breakage in the fiber polymer macromolecules producing the free radical parts in polymer chains. Free electrons in the argon plasma can perform such bond-breakage, especially at higher energies, due to an increase of cross sections for the processes which can break carbon-hydrogen, carbon-oxygen and carbon-carbon bonds. Cross sections for electron-induced breakage of carbon-hydrogen and carboncarbon bonds were measured for small molecules by many authors (Grill et al. 1993; Zheng and Srivastava 1996; Tian and Vidal 1998; Feil et al. 2006; Szymanska et al. 2014). Cross sections for breakage carbonoxygen and carbon hydroxyl bonds were measured for 


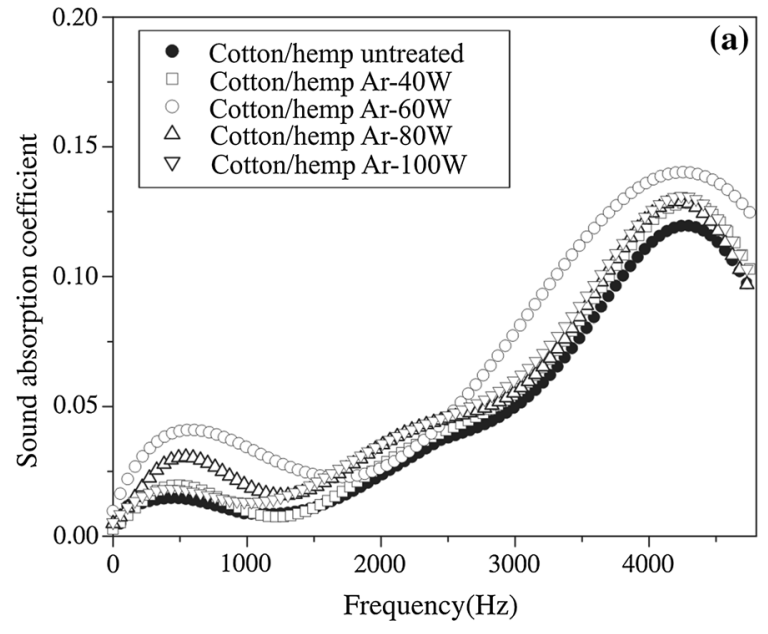

Fig. 1 Sound absorption coefficient for untreated and plasma treated samples: a samples made in a form of knitted fabrics for different plasma power applied. b Samples made in a form of

small molecules by Freund et al. (1990) and by Rejoub et al. (2003). These cross section data can serve for estimating of the rates of electron-induced bondbreaking processes in the case of polymer macromolecules with these bonds in their chains. The second mechanism which leads to polymer modification is induced by ion bombardment of the treated materials by ions generated in the argon plasma (Slepička et al. 2013). The rates for ionization of argon atoms and estimations of their density in plasma can be calculated by using methods which are already developed for the cases of nitrogen and carbon-monoxide plasmas (Popović et al. 2014; Aoneas et al. 2017). The excited argon atoms can also take part in the bondbreaking processes in polymer macromolecules. The excited atoms emit visible or ultraviolet (VUV) radiation during their relaxation processes, which can be absorbed by polymer molecules. Energy obtained in the absorption processes can lead to the bond-breaking processes in polymeric molecules. The excited atoms in metastable states can also cause the bond-breaking processes by the non-radiative mechanisms of energy transfer. The rates for excitation of argon atoms can be calculated by the methods already developed for the nitrogen and carbon-monoxide plasmas (Ristić et al. 2017, 2018).

According to the discussion above, at medium and high applied powers a great portion of excited argon atoms and ions are created in the plasma bulk. They interact with polymeric molecules in the plasma

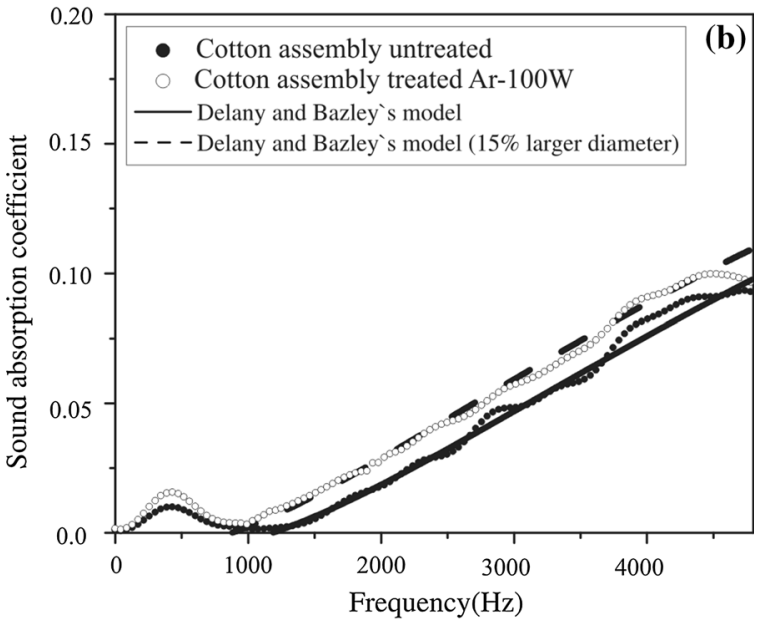

fiber assemblies and proposed theoretical results based on Delany-Bazley model for two different values of the fiber diameter

sheath and cause the bond-breaking processes between atoms in polymeric molecules (Slepička et al. 2013). At the same time, high energy electrons, populating the high-energy tail of electron energy distribution (the method for the calculation is given in Popović et al. 2014; Aoneas et al. 2017; Ristić et al. 2017, 2018) in plasma discharges have enough energy to take part in the energy transfer processes and to cause bond-breaking processes in polymer molecules, as well. All these bond-breaking processes make polymer macromolecules unstable, with plenty radical groups. The radical parts of polymer macromolecules, which consist commonly of carbon atoms, can either links with oxygen in oxidation processes or recombine their bonds.

\section{SEM analysis of macro-structural changes}

Additional analyses related to structural and chemical properties of the plasma treated cellulose materials were conducted. We employed a scanning electron microscope (SEM) technique to investigate the macrostructural changes of treated materials (Fig. 2a, b). One could easily notice the difference between the SEM micrographs of the untreated and plasma treated samples (Fig. 2a, b).

The sample of untreated cotton/hemp knitted fabric has an organized orientation of fibers while such organization for the plasma treated sample is compromised. Alongside, in the case of plasma treated 


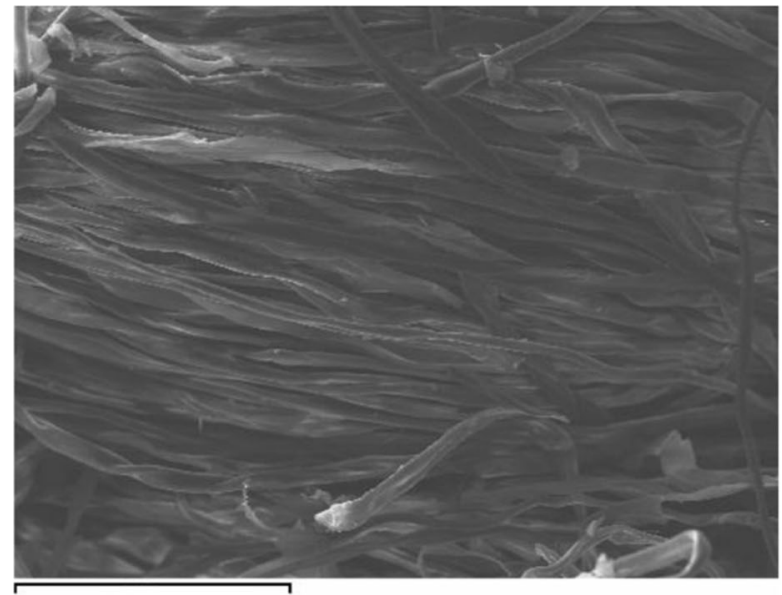

$200 \mu \mathrm{m}$

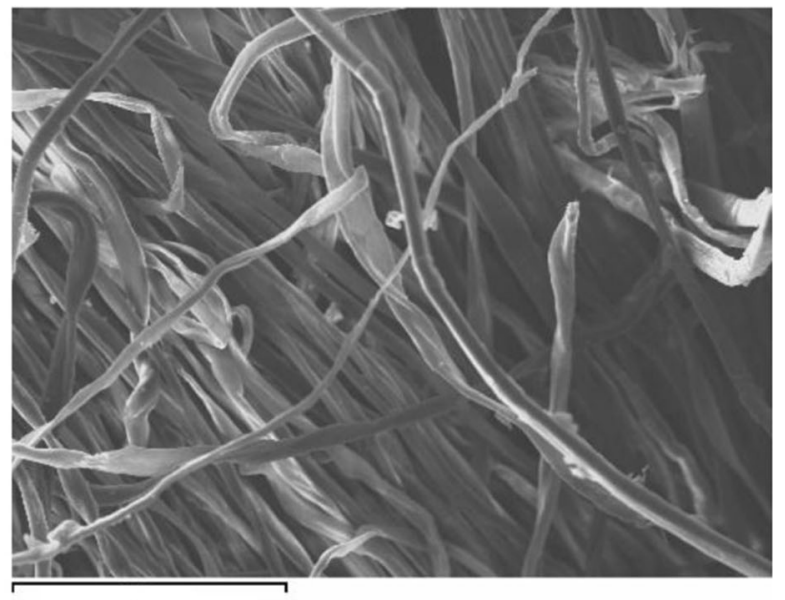

$200 \mu \mathrm{m}$

(a) untreated

(b) treated, $P=100 \mathrm{~W}$

Fig. 2 SEM micrographs of the a untreated, b plasma treated samples of material obtained by SEM

sample, there are clearly visible damages in the structure of the fibers. The fibers' surface becomes rougher due to the plasma treatment, i.e. impact of plasma bombardment and etching. The similar conclusions for surface modification of cellulosic fibers after the plasma treatment have been already reported by many authors (Xiangyu et al. 2006; Zhou et al. 2012; Ventura et al. 2016). In addition, the effect of the changes in the nanotopography of fibers induced by plasma treatments were reported (Calvimontes et al. 2011; Vasiljević et al. 2013). Here should be pointed out that the SEM analysis reported in this paper provides only the rough estimation of the surface modification of treated materials.

\section{XPS and EDAX characterizations}

To investigate further the impact of the plasma treatment on the natural cellulose fibrous materials, we analyzed the change of the chemical composition caused by the plasma treatment. We employed the X-ray photoelectron spectroscopy (XPS) and the energy-dispersive X-ray spectroscopy (EDAX) to determine the chemical composition of the surface of cellulose fibers. Figure $3 \mathrm{a}-\mathrm{c}$ shows the results of XPS analysis in the range $0-1000 \mathrm{eV}$ of the untreated samples, the samples immediately after and 3 days upon the plasma treatment, respectively. Upon the plasma treatment, the samples were exposed to the normal atmospheric condition. As it was expected, the

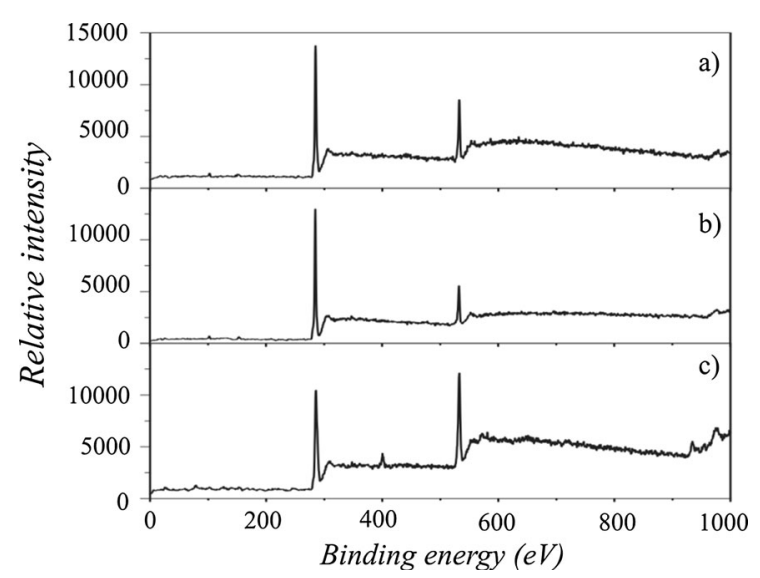

Fig. 3 XPS analyses of a untreated (pristine) sample, b sample analyzed immediately upon the plasma treatment, c sample analyzed 3 days upon the plasma treatment

pronounced XPS peaks belong to oxygen and carbon (534.7 eV and $286.7 \mathrm{eV}$, respectively). It could be noticed that the carbon-oxygen ratio changes due to the plasma treatment, i.e. the amount of oxygen decreases. The share of oxygen in the pristine samples is about $37 \%$ while the share of carbon is about $63 \%$. Immediately after the plasma treatment the share of oxygen decreases to $23 \%$, while the share of carbon increases to $77 \%$. The similar effect of decreasing the oxygen concentration on fiber surface of the treated cellulose material by the argon plasma has been observed by Sahin (2008). As the plasma treated samples are exposed to the normal atmospheric 
condition, the amount of oxygen increases, overcoming the values for the pristine sample and its share is $45 \%$, while the share of carbon is $50 \%$ and, additionally, the nitrogen is present $(403.1 \mathrm{eV})$ with the share of $5 \%$. The changing in carbon-oxygen ratio was additionally confirmed by the EDX analyses, which was conducted independently for the same samples. The effect of plasma treatment on the samples can be more precisely explained by the analysis of high resolution spectra for the pristine sample and the samples immediately after and 3 days upon the plasma treatment.

In Fig. $4 \mathrm{a}-\mathrm{c}$ it can be seen the results of the deconvolution of the C1s XPS peak spectra observed for the untreated (pristine) sample (Fig. 4a), and for the samples which spectra were observed immediately upon the plasma treatment (Fig. 4b) and 3 days after the plasma treatment (Fig. 4c), which in the meantime were exposed to the normal atmosphere. Due to the breakage of $\mathrm{C}-\mathrm{O}$ and $\mathrm{C}-\mathrm{C}$ links in cellulose macromolecules during the plasma treatment, the $\mathrm{O}-\mathrm{C}-\mathrm{O}$ and $\mathrm{C}-\mathrm{C}-\mathrm{O}$ peaks decrease in relation to the corresponding peaks for the pristine sample, which can be observed by comparing Fig. 4a, b. The same effect of the bond-breakage should lead to a decrease in $\mathrm{C}-\mathrm{OH}$ peak, but the part of broken $\mathrm{O}-\mathrm{C}-\mathrm{O}$ links becomes the insatiate $\mathrm{C}-\mathrm{O}$ links which resulted in an increase in the $\mathrm{C}-\mathrm{OH}$ peak. Figure $4 \mathrm{~b}$ shows the appearance of the pure $\mathrm{C}$ peak, which is also a consequence of the bondbreaking effect. In such way, the carbon atoms became the radicals, tending to bond the oxygen. Therefore, the oxygen from the atmosphere tend to be bonded to replace the detached $\mathrm{OH}$ groups and to satiate radical carbon atoms at broken $\mathrm{C}-\mathrm{C}$ bonds and at broken $\mathrm{O}-$ $\mathrm{C}-\mathrm{O}$ bond, which exists as insatiate $\mathrm{O}-\mathrm{C}^{*}$ radical bonds. The radical parts of polymer chains are unstable and such free radicals tend to be fast reduced under atmospheric conditions (Sabharwal et al. 1993). That is why, during the post-plasma oxidation process, the amount of oxygen increases until the broken carbon bonds are satiated (Zemljič et al. 2009). The effect of post oxidation can be seen at C1s XPS peak spectra in Fig. 4c), where we can recognize new peaks which belong to $\mathrm{O}-\mathrm{C}=\mathrm{O}, \mathrm{HC}=\mathrm{O}$ and $\mathrm{O}-\mathrm{CO}-\mathrm{O}$ bonds. This effect has been already observed and it is concluded that the Ar plasma treatments initiate reactions mainly associated with the cleavage of $\mathrm{C}-$ $\mathrm{C}$ links of pyranosidic rings, followed by ex situ post plasma oxidation which lead to the formation of $\mathrm{O}_{-}$
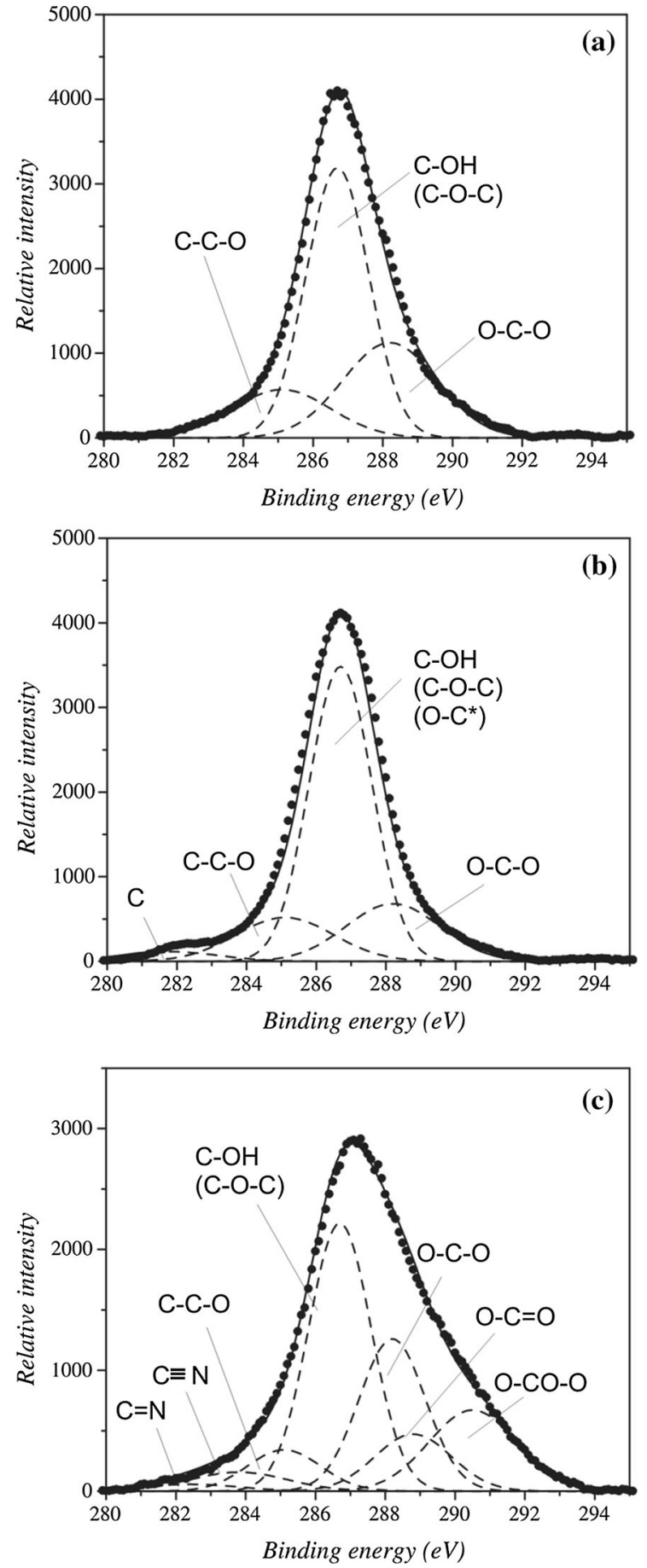

Fig. $4 \mathrm{C} 1 \mathrm{~s}$ region for a untreated (pristine) sample, b sample immediately upon the plasma treatment, c sample 3 days upon the plasma treatment, with the peak fitting components

$\mathrm{C}=\mathrm{O}, \mathrm{HC}=\mathrm{O}$ and $\mathrm{O}-\mathrm{CO}-\mathrm{O}$ groups, as reported in Hua et al. (1997). The effect of increasing the amount of oxygen due to the plasma treatment has been already 
confirmed by XPS analyses and reported by numerous authors (Wong et al. 1999; Kolarova et al. 2013; Vosmanska et al. 2014).

In Fig. $4 c$ one can see the additional peaks which correspond to $\mathrm{C}=\mathrm{N}$ and $\mathrm{C} \equiv \mathrm{N}$ bonds. The share of nitrogen in spectra is only $5 \%$, and its presence is a consequence of the activation of cellulose chains by argon plasma and the satiation processes of free radicals during the post treatment oxidation. In addition, a relative decrease in the central peak can be noticed. This peak belongs mainly to $\mathrm{C}-\mathrm{OH}$ link, but also to the intermediate $\mathrm{O}-\mathrm{C}^{*}$ and $\mathrm{C}-\mathrm{O}-\mathrm{C}$ links between the adjacent macromolecules. The intermediate $\mathrm{O}-\mathrm{C}^{*}$ links satiate during post-oxidation process and become commonly $\mathrm{O}-\mathrm{C}-\mathrm{O}$. $\mathrm{C}-\mathrm{OH}$ links are reestablished during post-oxidation processes and its number roughly remains the same as before treatment. The number of $\mathrm{C}-\mathrm{O}-\mathrm{C}$ links which point to the links between the adjacent cellulose macromolecules decreases.

In the light of the presented XPS results, the previously mentioned irreversibility of an increase in the SAC of the cellulose materials due to the plasma treatment can be easily understand. Namely, the pivotal processes which take place at the surface of the sample during the plasma treatment (such as the breakage in the cellulose chains, the cleavage of $\mathrm{C} 1-$ C2 linkages and breakage of the links between the adjacent macromolecules) are the irreversible ones. Both of these two effects lead to a decrease in the fiber stiffness, i.e. the fibers become more elastic for transversal oscillations. This is in accordance with the results reported by Yuan et al. (2004), which confirmed an increase in viscoelastic dissipation in plasma treated cellulose fibers. At the micro-mechanical level, an increase in fiber elasticity causes the amplitudes of the oscillations to become larger during the sound excitement and as a result, the amount of sound mechanical energy which they absorb is larger. It leads to an increase in the SAC as a consequence of the plasma treatments.

As a consequence of the noticed effect of breaking the links between the adjacent macromolecules, the packing density of cellulose chains in fibrils (in the fiber's surface layer) is reduced leading inevitably to an increase in the fiber diameter. The average diameter of the cotton fiber in the assemblies was $10 \mu \mathrm{m}$ and the diameter of the cotton and hemp fibers in the rib knitted fabrics was ranged between 10 and $20 \mu \mathrm{m}$. An increase in fiber diameter after the plasma treatment was not uniform but it was approximately $15 \%$. To confirm this, we compared the experimentally obtained SAC spectra of the cotton fibrous assemblies with the theoretical ones, which were obtained by applying Delany-Bazley model for predicting the acoustical characteristics of fibrous absorbent materials (Delany and Bazley 1970). The results of applying the Delany-Bazley model for two different values of the fiber's diameter are presented in Fig. 1b. The first one is the diameter of the untreated sample, and another one is the estimated diameter (about 15\% higher) of the plasma treated sample. It is clear that there is a good matching in the trend between the experimentally measured SAC spectra of untreated (pristine) sample and spectra obtained theoretically from the Delany-Bazley model. In the case of plasma treated sample, the experimentally measured spectrum agrees very well with SAC spectrum obtained by using the Delany-Bazley model for supposed $15 \%$ larger fibers' diameters. On the other hand, in accordance with the Delany-Bazley model, the increase in the diameter of the fiber causes the increase in the SAC. This obtained agreement supports our assumption that one of the reasons for an increase in the SAC after plasma treatment could be the larger diameter of fibers, which is the consequence of the bond-breaking processes between the adjacent cellulose macromolecules.

At the macroscopic level, an increase in the fiber diameter leads to an increase in the yarn diameter, due to which the size of the pores in the fabrics and assemblies is slightly reduced. Although this pore size reduction is probably not very pronounced from macroscopic point of view, we believe that this can additionally improve the sound absorption by an increase in the frictional resistance between the fibers and air. Bearing in mind that the cellulose knitted fabrics tested in this investigation are designed for clothing and home textile use, the obtained values of their SAC are to be expected (Honarvar et al. 2010; Yang et al. 2010; Rwawiire et al. 2017; Islam and Alam 2018). From that point of view, the effect of an increase in sound absorption by the plasma treatment of the fabrics is promising. We believe that the capacity of the plasma treatment for improving SAC will be even higher for cellulose fibrous materials designed for technical use (sound absorbing materials). The real challenge for scientists and engineers is 
to achieve the adequate technological and economic aspects of the plasma treatment of cellulose fibrous materials.

\section{Conclusion}

The modification of the acoustical properties of natural cellulose fibrous materials by the low-pressure radio-frequency argon plasma has been investigated. It has been clearly shown that the sound absorption coefficient of natural cellulose fibrous materials, both with directionally and randomly oriented fibers, was irreversibly increased due to the plasma treatment. In order to enlighten the mechanism of plasma modification of the acoustical properties, the analysis of the pivotal processes in the plasma-cellulose interaction was supported by detailed SEM/EDX and XPS analyses. The modification of the acoustical properties of the natural cellulose materials was related to their structural micro-mechanical changes, such as a decrease in the fibers' stiffness and an increase in their diameter. Further research will include different plasmas and their effect on sound absorption properties of technical textiles (higher thickness range, specific structure).

Acknowledgments This work was supported in a part by the Ministry of Education and Science of the Republic of Serbia by the Project No. 171016.

\section{References}

Aoneas MM, Vojnović MM, Ristić MM, Vićić MD, Poparić BG (2017) Ionization of CO in radio-frequency electric field. Phys Plasma 24:023502. https://doi.org/10.1063/1. 4975312

Arefi-Khonsari F, Tatoulian M (2008) Plasma processing of polymers by a low-frequency discharge with asymmetrical configuration of electrodes. In: d'Agostino R, Favia P, Kawai Y, Ikegami H, Sato N, Are-Khonsari F (eds) Advanced plasma technology. Wiley, New York, pp 137-170

Arenas JP, Crocker MJ (2010) Recent trends in porous soundabsorbing materials. Sound Vib 44(7):12-17

Arenas JP, Rebolledo J, del Rey R, Alba J (2014) Sound absorption properties of unbleached cellulose loose-fill insulation material. BioResources 9(4):6227-6240

Asdrubali F, Schiavoni S, Horoshenkov KV (2012) A review of sustainable materials for acoustic applications. Build Acoust 19(4):283-312
Attenborough K (1982) Acoustical characteristics of porous materials. Phys Rep 82(3):179-227

Baldwin MJ, Fewell MP, Haydon SC et al (1998) RF-plasma nitriding of stainless steel. Surf Coat Technol 98:1187-1191. https://doi.org/10.1016/S0257-8972(97)00150-3

Beradi U, Iannace G (2015) Acoustic characterization of natural fibers for sound absorption applications. Build Environ 94:840-852. https://doi.org/10.1016/j.buildenv.2015.05. 029

Beradi U, Iannace G (2017) Predicting the sound absorption of natural materials: best-fit-inverse laws for the acoustic impedance and the propagation constant. Appl Acoust 115:131-138. https://doi.org/10.1016/j.apacoust.2016.08. 012

Beradi U, Iannace G, Di Gabriele M (2017) Acoustic characterization of broom plant. J Nat Fibers 14(6):858-863. https://doi.org/10.1080/15440478.2017.1279995

Biot MA (1962) Generalized theory of acoustic propagation in porous dissipative media. $\mathrm{J}$ Acoust Soc Am 34(1962):1254-1264

Buksnowitz C, Adusumalli R, Pahler A, Sixta H, Gindl W (2010) Acoustical properties of lyocell, hemp, and flax composites. J Reinf Plast Compos 29(20):3149-3154. https://doi.org/10.1177/0731684410367533

Calvimontes A, Mauersberger P, Nitschke M et al (2011) Effects of oxygen plasma on cellulose surface. Cellulose 18:803-809. https://doi.org/10.1007/s10570-011-9511-5

Dahl MD, Rice EJ, Groesbeck DE (1990) Effects of fiber motion on the acoustic behavior on anisotropic, flexible fibrous materials. J Acoust Soc Am 87(1):54-66

Delany ME, Bazley EN (1970) Acoustical properties of fibrous absorbent materials. Appl Acoust 3:105-116

Dias T, Monaragala R (2006) Sound absorption in knitted structures for interior noise reduction in automobiles. Meas Sci Technol 17(9):2499-2505. https://doi.org/10.1088/ 0957-0233/17/9/018

Dias T, Monaragala R, Lay E (2007) Analysis of thick spacer fabrics to reduce automobile interior noise. Meas Sci Technol 18(7):1979-1991. https://doi.org/10.1088/09570233/18/7/026

Echeverria CA, Pahlevani F et al (2019) Engineered hybrid reinforced composites for sound absorption building applications. Resour Conserv Recycl 143:1-14. https://doi. org/10.1016/j.resconrec.2018.12.014

Fatima S, Mohanty AR (2011) Acoustical and fire-retardant properties of jute composite materials. Appl Acoust 72:108-114. https://doi.org/10.1016/j.apacoust.2010.10. 005

Feil S, Gluch K, Bacher A et al (2006) Cross sections and ion kinetic energy analysis for the electron impact ionization of acetylene. J Chem Phys 124:214307. https://doi.org/10. 1063/1.2202317

Fouladi MH, Ayub M, Nor MJM (2011) Analysis of coir fiber acoustical characteristics. Appl Acoust 72:35-42. https:// doi.org/10.1016/j.apacoust.2010.09.007

Freund RS, Wetzel RC, Shul RJ (1990) Measurements of electron-impactionization cross sections of $\mathrm{N}_{2}, \mathrm{CO}, \mathrm{CO}_{2}$, $\mathrm{CS}, \mathrm{S}_{2}, \mathrm{CS}_{2}$, and metastable $\mathrm{N}_{2}$. Phys Rev A 41(11):5861-5868

Garai M, Pompoli F (2005) A simple empirical model of polyester fiber materials for acoustical applications. Appl 
Acoust 66(12):1383-1398. https://doi.org/10.1016/j. apacoust.2005.04.008

Grace JM, Gerenser LJ (2003) Plasma treatment of polymers. J Dispers Sci Technol 24:305-341. https://doi.org/10.1081/ DIS-120021793

Grill V, Walder G, Scheier P et al (1993) Absolute partial and total electron impact ionization cross sections for $\mathrm{C}_{2} \mathrm{H}_{6}$ from threshold up to $950 \mathrm{eV}$. Int J Mass Spectrom Ion Process 129:31-42. https://doi.org/10.1016/0168-1176(93)87026-O

Honarvar MG, Jeddi AAA, Tehran MA (2010) Noise absorption modeling of rib knitted fabrics. Text Res J 80(14):1392-1404. https://doi.org/10.1177/0040517509357649

Hua ZQ, Sitaru R, Denes F, Young RA (1997) Mechanisms of oxygen- and argon-RF-plasma induced surface chemistry of cellulose. Plasmas Polym 2(3):199-224

Islam S, Alam SMdM (2018) Investigation of the acoustic properties of needle punched nonwoven produced of blend with sustainable fibers. Int $\mathbf{J}$ Cloth Sci Technol 30(3):444-458. https://doi.org/10.1108/IJCST.01.2018. 0012

Kljajević LM, Nenadović SS, Nenadović MT et al (2017) Structural and chemical properties of thermally treated geopolymer samples. Ceram Int 43:6700-6708. https://doi. org/10.1016/j.ceramint.2017.02.066

Kolarova K, Vosmanska V, Rimpelova S, Sorcik VS (2013) Effect of plasma treatment on cellulose fiber. Cellulose 20:953-961. https://doi.org/10.1007/s10570-013-9863-0

Krucinska I, Gliscinska E, Michalak M et al (2015) Soundabsorbing green composites based on cellulose ultra-short/ ultra-fine fibers. Text Res J 85(6):646-657. https://doi.org/ $10.1177 / 0040517514553873$

Kucuk M, Korkmaz Y (2012) The effect of physical parameters on sound absorption properties of natural fiber mixed nonwoven composites. Text Res J 82(20):2043-2053. https://doi.org/10.1177/0040517512441987

Marsh G (2003) Next step for automotive materials. Mater Today 6(4):36-43

Miki Y (1990) Acoustical properties of porous materialsmodifications of Delany-Bazley model. J Acoust Soc Jpn 11(1):19-24

Nick A, Becker U, Thoma W (2002) Improved acoustic behavior of interior parts of renewable resources in the automotive industry. J Polym Environ 10(3):115-118

Oldham DJ, Egan CA, Cookson RD (2011) Sustainable acoustic absorbers from the biomass. Appl Acoust 72:350-363. https://doi.org/10.1016/j.apacoust.2010.12.009

Parikh DV, Chen Y, Sun L (2006) Reducing automotive interior noise with natural fiber nonwoven floor covering systems. Text Res J 76(11):813-820. https://doi.org/10.1177/ 0040517506063393

Poll HU, Schladitz U, Schreiter S (2001) Penetration of plasma effects into textile structures. Surf Coat Technol 142-144:489-493

Popović MP, Vojnović MM, Aoneas MM et al (2014) Ionization of $\mathrm{N}_{2}$ in radio-frequent electric field. Phys Plasma 21:063504. https://doi.org/10.1063/1.4882438

Rejoub R, Morton CD, Lindsay BG, Stebbings RF (2003) Electron-impact ionization of the simple alcohols. J Chem Phys 118:1756-1760. https://doi.org/10.1063/1.1531631

Ristić MM, Aoneas MM, Vojnović MM, Poparić BG (2017) Excitation of electronic states of $\mathrm{N}_{2}$ in radio-frequency electric field by electron impact. Plasma Chem Plasma Process 37(5):1431-1443. https://doi.org/10.1007/s11090017-9826-6

Ristić MM, Aoneas MM, Vojnović MM, Galijaš SMD, Poparić BG (2018) Excitation of electronic states of CO in radiofrequency electric field by electron impact. Plasma Chem Plasma Process 38:903-916. https://doi.org/10.1007/ s11090-018-9892-4

Rwawiire S, Tomkova B et al (2017) Acoustic and thermal properties of a cellulose nonwoven natural fabric. Appl Acoust 116:177-183. https://doi.org/10.1016/j.apacoust. 2016.09.027

Sabharwal HS, Denes F, Nielsen L, Young RA (1993) Freeradical formation in jute from argon plasma treatment. Agric J Food Chem 41:2202-2207

Sahin HT (2008) RF-argon plasma induced surface modification of paper. Surf Rev Lett 15:503-508. https://doi.org/10. 1142/S0218625X08011652

Seddeq HS (2009) Factors influencing acoustic performance of sound absorptive materials. Aust J Basic Appl Sci 3(4):4610-4617

Shoshani Y, Rosenhouse G (1990) Noise absorption by woven fabrics. Appl Acoust 30:321-333

Shoshani Y, Yakubov Y (1999) A model for calculating the noise absorption capacity of nonwoven fiber webs. Text Res J 69(7):519-526

Slepička P, Kasalkova NS, Stranska E, Bačakova L, Švorčik V (2013) Surface characterization of plasma treated polymers for applications as biocompatible carriers. Express Polym Lett 7:535-545. https://doi.org/10.3144/expresspolymlett. 2013.50

Soltani P, Zerrebini M (2012) The analysis of acoustical characteristics and sound absorption coefficient of woven fabrics. Text Res J 82(9):875-882. https://doi.org/10.1177/ 0040517511402121

Soltani P, Zerrebini M (2013) Acoustic performance of woven fabrics in relation to structural parameters and air permeability. J Text Inst 104(9):1011-1016. https://doi.org/10. 1080/00405000.2013.771427

Stankovic S, Pavlovic S, Popovic D, Poparic G (2016) Potential of yarn folding in terms of sound absorption by rib knitted fabrics. In: Proceedings of the 16th world textile conference AUTEX 2016. University of Ljubljana, Faculty of Sciences and Engineering, Ljubljana

Szymanska E, Mason NJ, Krishnakumar E et al (2014) Dissociative electron attachment and dipolar dissociation in ethylene. Int J Mass Spectrom 365-366:356-364. https:// doi.org/10.1016/j.ijms.2014.01.006

Tang X, Kong D, Yan X (2018) Multiple regression analysis of a woven fabric sound absorber. Text Res J 89(5):855-866. https://doi.org/10.1177/0040517518758001

Thilagavathi G, Pradeep E et al (2010) Development of natural fiber nonwovens for applications as car interiors for noise control. J Ind Text 39(3):267-277. https://doi.org/10.1177/ 1528083709347124

Tian C, Vidal CR (1998) Cross sections of the electron impact dissociative ionization of $\mathrm{CO}, \mathrm{CH}_{4}$ and $\mathrm{C}_{2} \mathrm{H}_{2}$. J Phys B At Mol Opt Phys 31:895-909. https://doi.org/10.1088/09534075/31/4/031 
Vasile S, Van Langenhove L (2004) Automotive industry-a high potential market for nonwovens sound insulation. J Text Appar Technol Manag 3(4):1-5

Vasiljević J, Gorjanc M, Zaplotnik R et al (2013) Water-vapour treatment of cotton and polyster fibers. Mater Technol 47:379-384

Ventura H, Claramunt J, Navarro A et al (2016) Effects of wet/ dry-cycling and plasma treatments on the properties of flax nonwovens intended for composite reinforcing. Materials 9:93. https://doi.org/10.3390/ma9020093

Vidaurre EFC, Achete CA, Gallo F, Garcia D, Simao R, Habert AC (2002) Surface modification of polymeric materials by plasma treatment. Mater Res 5:37-41. https://doi.org/10. 1590/S1516-14392002000100006

Vosmanska V, Kolarova K, Rimpelova S, Svorcik VS (2014) Surface modification of oxidized cellulose haemostat by argon plasma treatment. Cellulose 21:2445-2456. https:// doi.org/10.1007/s10570-014-0328-x

Wang C-N, Torng J-H (2001) Experimental study of the absorption characteristics of some porous fibrous materials. Appl Acoust 62:447-459

Wong KK, Tao XM, Yuen CWM, Yeung KW (1999) Low temperature plasma treatment of linen. Text Res $\mathrm{J}$ 69:846-855

Xiang HX, Wang D, Liu H, Zhao N, Xu J (2013) Investigation on sound absorption properties of kapok fibers. Chin J Polym Sci 31(3):521-529. https://doi.org/10.1007/s10118013-1241-8

Xiangyu X, Yueping W, Xiaodan Z et al (2006) Effects on surface properties of natural bamboo fibers treated with atmospheric pressure argon plasma. Surf Interface Anal 38:1211-1217. https://doi.org/10.1002/sia.2378
Yang S, Yu W, Pan N (2010) Investigation of the sound-absorbing behavior of fiber assemblies. Text Res J 81(7):673-682. https://doi.org/10.1177/0040517510385177

Youngjoo N, Gilsoo C (2010) Sound absorption and viscoelastic property of acoustical automotive nonwovens and their plasma treatment. Fibers Polym 11:782-789. https://doi. org/10.1007/s12221-010-0782-5

Yuan X, Jayaraman K, Bhattacharyya D (2004) Effects of plasma treatment in enhancing the performance of woodfiberpolypropylene composites. Compos A 35:1363-1374

Zemljič LF, Persin Z, Stenius P (2009) Improvement of chitosan adsorption onto cellulosic fabrics by plasma treatment. Biomacromolecules 10:1181-1187. https://doi.org/10. 1021/bm801483s

Zheng SH, Srivastava SK (1996) Electron-impact ionization and dissociative ionization of acetylene. J Phys B At Mol Opt Phys 29:3235-3244. https://doi.org/10.1088/0953-4075/ 29/14/028

Zhou Z, Wang J, Huang C et al (2012) Influence of absorbed moisture on surface hydrophobization of ethanol pretreated and plasma treated ramie fibers. Appl Surf Sci 258: 4411-4416. https://doi.org/10.1016/j.apsusc.2011.12.126

Zulkifh R, Mohd Nor NR, Mat Tahir MF et al (2008) Acoustics properties of multi-layer coir fibers sound absorption panel. J Appl Sci 8(20):3709-3714

Zwikker C, Kosten CW (1949) Sound absorbing materials. Elsevier, New York

Publisher's Note Springer Nature remains neutral with regard to jurisdictional claims in published maps and institutional affiliations. 